\title{
Treatment of Hip Trochanteric Bursitis Using Hyaluronate Injections
}

\author{
Lauren Gorelick $^{1^{*}}$, Ayala Rozano-Gorelick ${ }^{2}$, Dror Robinson ${ }^{2 * \#}$, Ohad Marcus $^{3}$, \\ Samia Joubran ${ }^{4}$, Edward Ram ${ }^{5}$
}

${ }^{1}$ Department of Hand Surgery, Rambam Medical Center, Haifa, Israel; ${ }^{2}$ Head Orthopedic Research Unit and Foot and Ankle Service Hasharon Hospital, Rabin Medical Center Affiliated with Sackler Faculty of Medicine, Tel Aviv University, Petah Tikwa, Israel; ${ }^{3}$ Department of Psychology, Tel-Hai Academic College, Tel-Hai, Israel; ${ }^{4}$ The Bruce Rappaport Faculty of Medicine, Techion-Israel Institute of Technology and Emek Medical Center, Haifa, Israel; ${ }^{5}$ Division of General Surgery, Rabin Medical Center-Campus Golda, Sackler School of Medicine, Tel Aviv University, Tel Aviv, Israel.

Email: \#dror@cartiheal.com

Received January $12^{\text {th }}, 2013$; revised February $23^{\text {rd }}, 2013$; accepted March $2^{\text {nd }}, 2013$

Copyright (C) 2013 Lauren Gorelick et al. This is an open access article distributed under the Creative Commons Attribution License, which permits unrestricted use, distribution, and reproduction in any medium, provided the original work is properly cited.

\begin{abstract}
Trochanteric bursitis is a common cause of musculoskeletal pain and often requires medical intervention and should be distinguished from sciatica and irradiating pain of pelvic and spinal origin. Previously, the etiology of the trochanteric pain syndrome was thought to be caused by inflammation. The current study was performed in order to assess the efficacy of trochanteric injections. Methods: 158 patients were treated for trochanteric bursitis (132 females/26 males, range $22-88$ years). 59b were treated with corticosteroid injection, 60 with hyaluronate and 39 were injected using a combination of both. Patients were followed by the HOOS score for a minimum of 12 months. Results: Pre-operative HOOS scores were similar in all groups. Following injection, the HOOS score increased from $27 \pm 4$ to $66 \pm 2$ after six months and $77 \pm 4$ after a year. At 12-month follow-up, the average score of patients treated by corticosteroids injection was $44 \pm 7$ compared with $62 \pm 8$ for the hyaluronate injected group and $64 \pm 6$ for the combination injection group. Discussion: It appears that injection therapy is highly efficacious for treating trochanteric bursitis. The effect of hyaluronate or hyaluronate and steroid combination appears to be longer lasting than that of steroid alone.
\end{abstract}

Keywords: Hip; Trochanteric Bursitis; Hyaluronic Acid; Bursitis

\section{Introduction}

Bursitis is a common cause of musculoskeletal pain and often requires medical intervention. It should be distinguished from arthritis, fracture, tendinitis, and nerve pathology. Trochanteric bursitis is common and should be distinguished from sciatica and irradiating pain of pelvic and spinal origin. Most patients respond to nonsurgical management, including ice, activity modification, and nonsteroidal anti-inflammatory drugs.

The etiology of this syndrome is not completely clear, previously, the etiology of the trochanteric pain syndrome was thought to be caused by inflammation of the subgluteus maximus bursa (i.e., bursitis). Recently, MRI and ultrasound studies have brought into serious doubt the idea that bursitis is the etiology for trochanteric pain. Indeed, a histological evaluation has shown that the tis-

\footnotetext{
*Those authors equally contributed to this work.

\#Corresponding author.
}

sues are composed of primarily fibro-adipose tissue with no signs of acute or chronic inflammation [1]. Other authors have found an association between increase in trochanteric width compared with the iliac wing width and trochanteric bursitis [2]. Injection therapy is considered quite efficient with over 60 percent pain alleviation [3]; however, relapse is fairly common. There are inherent dangers to injection steroids anywhere in the body [4], but in the vicinity of tendons the risk is aggravated by the possibility of tendon tears. An alternative injectable medication is hyaluronate. There is a growing body of evidence supporting the use of hyaluronan (HA) in patients with adhesive capsulitis of the shoulder, although the mechanisms of the effect have not yet been clarified. It has been shown that in adhesive capsulitis of the shoulder, histological findings consistently demonstrated chronic nonspecific inflammation with synovial hyperplasia, proliferation of vessels and fibroblasts, and increased amount 
of extracellular matrix [5]. Hyaluronate significantly and dose-dependently inhibited cell proliferation and decreased the expression levels of mRNA for adhesion-related procollagens and cytokines. It is thus possible that a similar therapeutic effect be achieved using hyaluronate injections in the trochanteric bursa. The use of hyaluronate injections has been routine in our practice for the last 15 years. The following study is a retrospective evaluation of a consecutive series of patients treated with hyaluronate and compared with corticosteroids injection and combination therapy.

\section{Methods}

\subsection{Patients}

This is a retrospective evaluation of a consecutive series consisting of 158 patients that were treated for trochanteric bursitis [TB] (132 females/26 males). The average age was 63 years (range $22-88$ years). Fifty nine of the patients were treated with corticosteroid injection (betamethasone dipropionate 5 milligrams and betamethasone sodium phosphate 2 milligrams). Sixty of the patients were treated with hyaluronate (Ostenil, TRB Chemedica International S.A., 1211 Geneva, Switzerland). Thirty-nine of the patients were injected using a combination of hyaluronate and steroids (as described above).

\subsection{Trochanteric Bursitis Diagnosis}

The diagnosis was made as suggested by Brinks and coworkers [6]: "TB was diagnosed when the patient complained of pain persisting for more than 1 week in the lateral region of the hip, and tenderness to palpation of the greater trochanter, reproducing the patient's pain, was found on physical examination". All patients underwent at least one month of conservative treatment consisting of twice weekly standard physiotherapy regimen of physical strengthening of the gluteus medius and electrotherapy of the affected region. Treatment with non-steroidal anti-inflammatory agents was given to some of the patients as per family decision.

\subsection{Inclusion Criteria to Be Reported in This Series}

1) Diagnosis of TB as described above;

2) Failure of one month of conservative therapy;

3) Oral agreement to injection therapy.

\subsection{Exclusion Criteria from This Series}

1) Patients who were unable to understand the questionnaires;

2) Patients who had consulted their general practitioner with the same symptoms in the previous year and had received any intervention except the conservative therapy described above;

3) Patients who were operated on in the same region, or who had a systemic neurological or rheumatologic disorder;

4) Patients suffering from chronic low back pain or sciatica as per medical records;

5) Diabetes mellitus.

\subsection{Choice of Therapy}

Patients were offered a choice between injections of either medication. Due to pricing considerations the patient's decision was based on financial ability and preferences as anxiety from steroid injections and their complications is rather prevalent.

\subsection{Treatment Effect Assessment}

Patients were assessed using a back-translated HOOS (www.koos.nu/HOOSEng.pdf) version (Hebrew and Arabic). The questionnaires were self-filled by the patients, and a research assistant verified questionnaire filling. In addition a standardized VAS score was filled out in answer to the question: "What number would you give your pain right now?" (the scale employed is not horizontal but vertical [7] and thus eliminates bias stemming from writing directionality in our patient population).

\subsection{Statistical Analysis}

Statistical analysis was performed using the SPSS statistical program. ANOVA with post-hoc analysis was used. Between-group differences in the primary outcome were analyzed based on the intention-to-treat principle. Between-group differences in continuous outcome measures were analyzed with repeated measures for general linear models. A difference at the 0.05 level is termed significant.

Effect sizes were calculated as adjusted difference in outcome divided by baseline standard deviation of the outcome. From the clinical standpoint effect sizes of 0.2 to 0.5 are considered small, and 0.5 to 0.8 moderate, whereas greater than 0.8 indicates a large clinical effect [8].

\section{Results}

\subsection{HOOS Score}

The HOOS score was evaluated for the entire cohort. The HOOS score increased from $27 \pm 4$ to $66 \pm 2$ after six months and $77 \pm 4$ after a year (Figure 1). The pre-injection average score was similar in the three groups. A significant difference was found between the groups (Figure 2, ANOVA, $p<0.05$ ), the average score of patients treated by corticosteroids injection was $44 \pm 7$ as compared with $62 \pm 8$ for the hyaluronate injected group and $64 \pm 6$ for the combination injection group. There was a 
time interaction with inter-group difference with time. In the corticosteroid group the average score significantly improved from $26 \pm 4$ to $52 \pm 7$ at six months but did not improve further at 12 months $(53 \pm 6)$. The time-related behaviour was different in the hyaluronate group with a pre-injection average of $27 \pm 3$ increasing to $74 \pm 5$ at six months, and to $90 \pm 9$ at 12 months. The combination therapy group had a similar time-related behavior to the hyaluronate group (Table 1). Effect size was 0.9 for the hyaluronate and combination therapy groups and 0.5 for the corticosteroids group.

\subsection{VAS Scale}

VAS scale declined over time for the entire cohort from

\section{Change in HOOS Score following}

Injection Therapy Entire Cohort $(n=158)$

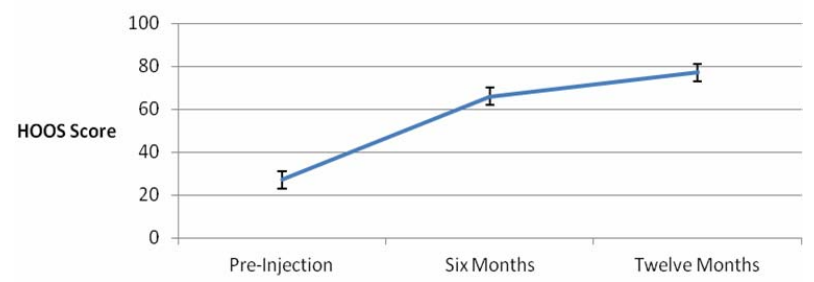

Figure 1. Improvement in HOOS score over the course of one year is significant for the entire cohort, indicating the limited lifespan of TB complaints.
10 to 2.4 after a year. There was a significant inter-group difference of the VAS scores with average VAS of the corticosteroids treated group higher $(5.5 \pm 1)$ than the hyaluronate group $(4.1 \pm 1)$ and the combination therapy group $(4 \pm 1.5)$. There is a time-dependent intergroup difference with a steep decline from pre-injection to the six weeks mark and a significant increase at later time points of 3 months and six months. The scale at twelve months is similar to that at six months (Table 2). The time dependence in the hyaluronate and the combination therapy groups is different with a continuing significant
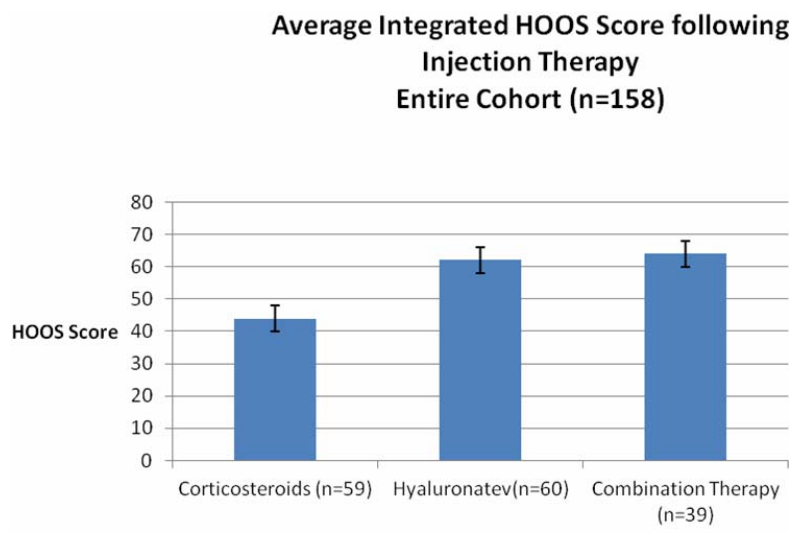

Figure 2. Integrated average HOOS score during one year follow-up in various groups. Average score of different treatment groups integrating all time-points. The integrative statistic allows appreciation of the treatment effect over time compared with a high pre-injection average of $10 \pm 1$.

Table 1. Average HOOS score variation with time after injection.

\begin{tabular}{|c|c|c|c|c|}
\hline & Entire Cohort & Corticosteroid & Hyaluronate & Combination Therapy \\
\hline $\begin{array}{l}\text { Time after } \\
\text { Injection }\end{array}$ & HOOS Score (average $\pm \mathrm{SD}^{*}$ ) & HOOS Score (average $\pm \mathrm{SD}^{*}$ ) & HOOS Score (average $\pm \mathrm{SD}^{*}$ ) & HOOS Score (average $\pm \mathrm{SD}^{*}$ ) \\
\hline Pre-Injection & $27 \pm 4$ & $26 \pm 4$ & $27 \pm 3$ & $27 \pm 4$ \\
\hline 6 Months & $66 \pm 2$ & $52 \pm 7$ & $74 \pm 5$ & $71 \pm 7$ \\
\hline
\end{tabular}

Table 2. Average VAS scale variation with time after injection.

\begin{tabular}{|c|c|c|c|c|}
\hline & Entire Cohort & Corticosteroid & Hyaluronate & Combination Therapy \\
\hline $\begin{array}{l}\text { Time after } \\
\text { Injection }\end{array}$ & HOOS Score (average $\pm \mathrm{SD}^{*}$ ) & HOOS Score (average $\pm \mathrm{SD}^{*}$ ) & HOOS Score (average $\pm \mathrm{SD}^{*}$ ) & HOOS Score (average $\pm \mathrm{SD}^{*}$ ) \\
\hline Pre-Injection & $10 \pm 1$ & $10 \pm 1$ & $10 \pm 1$ & $10 \pm 1$ \\
\hline 6 Weeks & $3.3 \pm 2$ & $3.9 \pm 1.5$ & $3.7 \pm 1$ & $2.5 \pm 1.5$ \\
\hline 3 Months & $3.5 \pm 2$ & $4.3 \pm 2$ & $3.2 \pm 1$ & $3.1 \pm 1$ \\
\hline 6 Months & $3.5 \pm 1.5$ & $4.7 \pm 2$ & $2.8 \pm 1.5$ & $3 \pm 1$ \\
\hline 12 Months & $2.4 \pm 1$ & $4.8 \pm 1$ & $1 \pm 1$ & $1.5 \pm 1$ \\
\hline
\end{tabular}

* $\mathrm{SD}=$ Standard Deviation. 
drop during the one year of follow-up.

\section{Discussion}

The current study appears to demonstrate that there is an ameliorative effect of steroid and hyaluronate injections in trochanteric bursitis. The pain relief appears to be significant with large effect size for both the hyaluronate and combination therapy groups. The effect of steroids appears to be short lived and this observation concurs with the finding comparing effects of steroids and hyaluronate in knee osteoarthritis [9]. The basic pathology underlying the symptoms is not fully known. However, inflammation does not appear to be involved in the basic pathological mechanism as histology and MRI do not indicate obvious signs of inflammation. The rationale for hyaluronate injection rests with its known anti-inflammatory effects as well as the possibility that its presence will restore normal tissue function. Indeed, previous studies have indicated that hyaluronate injections in the knee serve to ameliorate knee function and increase muscle strength by an unknown mechanism that does not occur with steroid injections $[10,11]$. It should be remembered that steroid injection particularly in diabetics is likely to raise glucose levels [12]. As a large proportion of the population is diabetic, this consideration limits the applicability of injection therapy in a significant proportion of patients.

The possible mechanism of action of hyaluronate in trochanteric bursitis appears to be complicated. The disorder is apparently non-inflammatory. However, it is known that hyaluronate plays a significant role during development, wound healing and regeneration. It enhances muscle progenitor cell recruitment and inhibits premature myotube fusion, implicating a role for this glycosaminoglycan in functional repair [13]. Indeed, the presence of hyaluronic acid in infarcted heart muscle appears to allow better left ventricular wall function and enhance the limited repair capacity [14].

The current study appears to indicate that hyaluronate injection is an acceptable alteranative to steroid injections for the treatment of trochanteric bursitis. The effect size is larger with hyaluronate injections, and lasts longer. Limitations of the current study include its design being retrospective, and thus the groups were not randomized. A further prospective randomized clinical trial should be done prior to making a clear cut recommendation that hyaluronate injections are superior to steroid injections in the treatment of this syndrome.

\section{REFERENCES}

[1] F. Silva, T. Adams, J. Feinstein and R. A. Arroyo, "Trochanteric Bursitis: Refuting the Myth of Inflammation," Journal of Clinical Rheumatology, Vol. 14, No. 2, 2008, pp. 82-86. doi:10.1097/RHU.0b013e31816b4471

[2] N. K. Viradia, A. A. Berger and L. E. Dahners, "Relationship between Width of Greater Trochanters and Width of Iliac Wings in Tronchanteric Bursitis," American Journal of Orthopedics, Vol. 40, No. 9, 2011, pp. E159E162.

[3] P. Walker, S. Kannangara, W. J. Bruce, D. Michael and H. Van der Wall, "Lateral Hip Pain: Does Imaging Predict Response to Localized Injection?" Clinical Orthopedics and Related Research, Vol. 457, 2007, pp. 144-149.

[4] M. B. Stephens, A. I. Beutler and F. G. O'Connor, "Musculoskeletal Injections: A Review of the Evidence," American Family Physician, Vol. 78, No. 8, 2008, pp. 971-976.

[5] M. Nago, Y. Mitsui, M. Gotoh, K. Nakama, I. Shirachi, F. Higuchi and K. Nagata, "Hyaluronan Modulates Cell Proliferation and mRNA Expression of Adhesion-Related Procollagens and Cytokines in Glenohumeral Synovial/ Capsular Fibroblasts in Adhesive Capsulitis," Journal of Orthopaetic Research, Vol. 28, No. 6, 2010, pp. 726-731.

[6] A. Brinks, R. M. van Rijn, A. M. Bohnen, G. L. Slee, J. A. Verhaar, B. W. Koes and S. M. Bierma-Zeinstra, "Effect of Corticosteroid Injection for Trochanter Pain Syndrome: Design of a Randomised Clinical Trial in General Practice," BMC Musculoskeletal Disorders, Vol. 8, 2007, pp. 95-99. doi:10.1186/1471-2474-8-95

[7] S. Kaasalainen and J. Crook, "An Exploration of Seniors' Ability to Report Pain," Clinical Nursing Research, Vol. 13, No. 3, 2004, pp. 199-215. doi: $10.1177 / 1054773804265692$

[8] D. T. Felson, J. J. Anderson, M. Boers, C. Bombardier, D. Furst, C. Goldsmith, L. M. Katz, R. Lightfoot Jr., H. Paulus and V. Strand, "American College of Rheumatology Preliminary Definition of Improvement in Rheumatoid Arthritis," Arthritis \& Rheumatism, Vol. 38, No. 6, 1995, pp. 727-735. doi:10.1002/art.1780380602

[9] D. Caborn, J. Rush, W. Lanzer, D. Parenti and C. Murray, "A Randomized, Single-Blind Comparison of the Efficacy and Tolerability of Hylan G-F 20 and Triamcinolone Hexacetonide in Patients with Osteoarthritis of the Knee," Journal of Rheumatology, Vol. 31, No. 2, 2004, pp. 333343.

[10] A. Skwara, R. Ponelis, C. O. Tibesku, D. Rosenbaum and S. Fuchs-Winkelmann, "Gait Patterns after Intraarticular Treatment of Patients with Osteoarthritis of the KneeHyaluronan versus Triamcinolone: A Prospective, Randomized, Doubleblind, Monocentric Study," European Journal of Medical Research, Vol. 14, No. 4, 2009, pp. 157-164.

[11] A. Skwara, C. D. Peterlein, C. O. Tibesku, D. Rosenbaum and S. Fuchs-Winkelmann, "Changes of Gait Patterns and Muscle Activity after Intraarticular Treatment of Patients with Osteoarthritis of the Knee: A Prospective, Randomised, Doubleblind Study," The Knee, Vol. 16, No. 6, 2009, pp. 466-472. doi:10.1016/i.knee.2009.03.003

[12] G. S. Habib and W. Miari, "The Effect of Intra-Articular Triamcinolone Preparations on Blood Glucose Levels in Diabetic Patients: A Controlled Study," Journal of Clinical Rheumatology, Vol. 17, No. 6, 2011, pp. 302-305. 
doi:10.1097/RHU.0b013e31822acd7c

[13] S. Calve, J. Isaac, J. P. Gumucio and C. L. Mendias, "Hyaluronic Acid, HAS1 and HAS2 Are Significantly Upregulated during Muscle Hypertrophy," American Journal of Physiology: Cell Physiology, Vol. 303, No. 5, 2012, pp. C577-C588. doi:10.1152/ajpcell.00057.2012
[14] E. Tous, J. L. Ifkovits, K. J. Koomalsingh, T. Shuto, T. Soeda, N. Kondo, J. H. Gorman III, R. C. Gorman and J. A. Burdick, "Influence of Injectable Hyaluronic Acid Hydrogel Degradation Behavior on Infarction-Induced Ventricular Remodeling," Biomacromolecules, Vol. 12, No. 11, 2011, pp. 4127-4135. doi:10.1021/bm201198x 